\title{
Serotypes, antimicrobial profiles, and public health significance of Salmonella from camels slaughtered in Maiduguri central abattoir, Nigeria
}

\author{
Ibrahim A. Raufu' ${ }^{1}$, Ismail A. Odetokun ${ }^{2}$, Fatai S. Oladunni ${ }^{1}$ Mohammed Adam ${ }^{3}$, Ubaidat T. Kolapo ${ }^{4}$, Ganiu J. Akorede ${ }^{5}$, \\ Ibraheem M. Ghali ${ }^{2}$, James A. Ameh ${ }^{6}$ and Abdulganiyu Ambali ${ }^{7}$
}

1. Department of Veterinary Microbiology, Faculty of Veterinary Medicine, University of Ilorin, Ilorin, Nigeria; 2. Department of Veterinary Public Health and Preventive Medicine, University of Ilorin, Nigeria; 3. Department of Veterinary Pathology, University of Ilorin, Nigeria; 4. Department of Veterinary Parasitology and Entomology, University of Ilorin, Nigeria; 5. Department of Veterinary Pharmacology and Toxicology, University of Ilorin, Nigeria; 6. Department of Veterinary Microbiology and Parasitology, University of Abuja, Nigeria; 7. Department of Veterinary Medicine, University of Ilorin, Nigeria.

Corresponding author: Ibrahim A. Raufu, e-mail: raufuib@yahoo.com, IAO: odetokun.ia@unilorin. edu.ng, FSO: kanmi01@gmail.com, MA: adam.m@unilorin.edu.ng, UTK: kolapo.tu@unilorin.edu.ng,

GJA: akoredegj@unilorin.edu.ng, IMG: drghalimohd@gmail.com, JAA: jamesameh10@gmail.com, AA: aambali076@yahoo.com

Received: 24-03-2015, Revised: 01-08-2015, Accepted: 12-08-2015, Published online: 15-09-2015

doi: 10.14202/vetworld.2015.1068-1072 How to cite this article: Raufu IA, Odetokun IA, Oladunni FS, Adam M, Kolapo UT, Akorede GJ, Ghali IM, Ameh JA, Ambali A (2015) Serotypes, antimicrobial profiles and public health significance of Salmonella from camels slaughtered in Maiduguri central abattoir, Nigeria, Veterinary World 8(9):1068-1072.

\begin{abstract}
Aim: This study aimed at determining the serotypes, antimicrobial profiles, and public health importance of Salmonella strains from camels slaughtered at Maiduguri central abattoir, Nigeria.

Materials and Methods: Two hundred samples were obtained from camel comprising of intestines, feces, liver, and spleen ( $\mathrm{n}=50$ each). Non-lactose fermenting dark center Salmonella colonies were identified using standard biochemical techniques, serotyped and subjected to antimicrobial susceptibility test using minimum inhibition concentration method.

Results: Out of the 200 samples collected, 17 were Salmonella positive (spleen=7, intestine=6, feces=3, and liver=1) with a prevalence of 8.5\%. Five serotypes comprising Salmonella Eko, 7 (3.5\%), Salmonella Uganda, 4 (2.0\%), Salmonella Amager, 2 (1.0\%), Salmonella Westhampton, 2 (1.0\%), and Salmonella Give, $2(1.0 \%)$ were incriminated. Majority of the serotypes were sensitive to the antimicrobials, but one Salmonella Amager exhibited resistance to streptomycin, and one each of Salmonella Uganda and Salmonella Eko were resistant to sulfamethoxazole.
\end{abstract}

Conclusion: This study revealed the prevalence and the antibiotic resistance profile of newly emerging Salmonella from camels in the northeast of Nigeria, which can serve as a means for the transmission of Salmonella to human. Therefore, there is a need for the establishment of national Salmonella surveillance and control programs.

Keywords: abattoir, antimicrobial profiles, camel, Nigeria, Salmonella serotypes, public health.

\section{Introduction}

Camel is a potential source of meat protein in sub-Sahara Africa, the meat is consumed to meet the nutritional requirements in the form of animal protein. Over 2,600 Salmonella species are associated with different hosts and virulence [1]. Members of Salmonella enterica subspecies enterica are widely distributed in the environment and the gastrointestinal tracts of animals.

In most developed countries, the major causes of human salmonellosis are Salmonella Typhimurium and Salmonella Enteritidis. However, other serotypes are common in some geographical regions in association with human salmonellosis [2-4]. Infections due to Salmonella serotypes are regarded as public health problems worldwide. Salmonella prevalence differs between animal species, and the epidemiology of

Copyright: The authors. This article is an open access article licensed under the terms of the Creative Commons Attributin License (http:// creative commons.org/licenses/by/2.0) which permits unrestricted use, distribution and reproduction in any medium, provided the work is properly cited. salmonellosis is quite complex due to myriads routes of infection transmission, such routes include transmission from human to animal, from feed to animal, and from animal to animal. Despite the large number of Salmonella serotypes, most infections are caused by a minute number of newly emerging serotypes [5].

Aside from Salmonella being a major cause of severe illnesses, the emergence of multidrug-resistant (MDR) Salmonella strains remains a serious threat to public health; the emergence of resistance to antimicrobials by Salmonella from food animals can seriously compromise the treatment of these infections [6]. More importantly, they have been implicated as a major donor of resistance genes to other pathogens or commensals in the gastrointestinal tract [7]. The development of MDR bacteria is usually enhanced by the administration of antimicrobials in food animals.

Third generation cephalosporins and fluoroquinolones are preferred drugs of choice in the management of human invasive salmonellosis; though, fluoroquinolones are also prescribed and administered for many indications in veterinary practices [8]. 
Salmonellosis has been reported in camels with enteritis [9], nevertheless apparently healthy camels could be carriers of Salmonella species [10]. The progressive increase in multi-antimicrobial resistant Salmonella strains from human has been associated with indiscriminate administration of antimicrobial agents in food animal production, there are also reports of the spread of antimicrobial resistance through the food chain resulting in a major public health issue [11-13]. In developing countries like Nigeria, Salmonella and other zoonotic bacterial pathogens are not routinely cultured, and resistance to commonly employed antimicrobials in public health and veterinary practices is rarely determined.

This study was aimed at determining the serotypes, the antimicrobial resistance patterns and public health importance of Salmonella from camels slaughtered for human consumption at Maiduguri central abattoir in the northeastern Nigeria.

\section{Materials and Methods \\ Ethical approval}

This study does not require ethical approval; samples were collected from slaughtered camels at Government approved slaughter houses.

\section{Study location}

Maiduguri is located in the arid zone of Borno State covering an area of about $69,436 \mathrm{~km}^{2}$ and is situated within latitude $11^{\circ} 50^{\prime} 46^{\prime \prime} \mathrm{N}$ and longitude $13^{\circ}$ $08^{\prime} 29^{\prime}$ E. It is in the sub-Saharan region with low records of rainfall. The area is in the tropical continental north associated with dry period of 4-8 months (October to May), followed by a short rainy season (late June to early October). The state is located in the North Eastern corner of Nigeria and shares boundaries with Chad to the North East, Cameroon to the East and Adamawa State to the South West. According to the 2005 census, the population is estimated to be $4,558,668$ and ranked 12th in the country. Agriculture and livestock husbandry forms the mainstay of the state economy.

\section{Collection of samples and bacterial isolation}

Two hundred samples were randomly collected with 17 samples on average (comprising of spleen, feces, intestine and liver ( $\mathrm{n}=50$ each) per sampling trip from different camels slaughtered at three different abattoirs located in Maiduguri Metropolitan (comprising central abattoir, Monday, and Gamboru markets), on a weekly basis from April to September, 2010.

Twenty-five gram each of spleen, feces (direct from the rectum), intestine and liver were aseptically collected from apparently healthy slaughtered camels (male with age ranging between 3 and 6 years) with a universal sample bottles containing $225 \mathrm{ml}$ of nutrient broth (Laboratarios Britania, Buenos Aires, Argentina) and transported in ice box to the veterinary microbiology laboratory of the Faculty of Veterinary Medicine, University of Maiduguri. Samples were incubated at $37^{\circ} \mathrm{C}$ overnight for $18-24 \mathrm{~h} .1 \mathrm{ml}$ of the non-selective pre-enriched culture was inoculated into $9 \mathrm{ml}$ selective broth of Selenite - F (Laboratarios Britania, Buenos Aires, Argentina) and incubated overnight at $37^{\circ} \mathrm{C}$ for $24 \mathrm{~h}$.

After enrichment, a loop full of the culture was streaked on Deoxycholate Citrate Agar (Park Scientific, Northampton, UK), incubated at $37^{\circ} \mathrm{C}$ for $24 \mathrm{~h}$. Discrete non-lactose fermenting dark center colonies were picked and streaked (subcultured) onto xylose lysine deoxycholate (XLD) agar (Oxoid Ltd., Hampshire, UK) and incubated for $18-24 \mathrm{~h}$ at $37^{\circ} \mathrm{C}$.

Presumptive Salmonella isolates (presumptive) showing pink/red color with dark center on XLD were picked and confirmed by biochemical characterization in accordance with the standard techniques [14]. The presumptive Salmonella isolates were subsequently streaked on nutrient agar (Fluka Biochemika, Steinheim, Germany) slants and incubated at $37^{\circ} \mathrm{C}$ for $24 \mathrm{~h}$ and stored in the refrigerator at $4{ }^{\circ} \mathrm{C}$ for serotyping and antimicrobial susceptibility tests.

\section{Serotyping}

Presumptive Salmonella isolates were shipped to World Health Organization (WHO) National and Shigella Center, Bangkok, Thailand for serotyping, this was performed by slide agglutination method, somatic $(\mathrm{O})$ and flagella $(\mathrm{H})$ antigens were characterized by agglutination using hyper immune sera ( $\mathrm{S}$ and A Reagents Laboratory, Ltd., Bangkok, Thailand) and serotypes were classified based on the KauffmannWhite scheme [15].

\section{Antimicrobial susceptibility test}

Minimum inhibition concentration (MIC) determinations were carried out on all the isolates at Denmark Technical University (DTU-Food), Denmark [16], using a commercial dehydrated panel (TREK Diagnostic Systems Ltd., East Grinstead, England) as summarized below.

\section{Standardization of inoculum}

From a pure culture on a blood agar plate 3-4 colonies were picked and suspended in $4 \mathrm{ml}$ saline in tubes and thoroughly mixed, this was adjusted to McFarland standard 0.5 , this was calibrated before use and gently turned with the suspensions upside-down before measuring. The turbidity of inoculum was adjusted to match the standard. The McFarland 0.5 suspension was diluted by mixing $50 \mu 1 \mathrm{McF}$ arland 0.5 into $10 \mathrm{ml}$ broth, the suspension was subsequently used for inoculation within $15 \mathrm{~min}$ to prevent further growth.

\section{Inoculation and Incubation}

The microtitre plates containing the antimicrobials were inoculated with $50 \mu \mathrm{l}$ of the inoculum suspension with the aid a Sensititre automatic inoculator (TREK Diagnostic Systems Ltd., East Grinstead, England). Plates were then sealed with the adhesive and incubated at $37^{\circ} \mathrm{C}$ for $18-22 \mathrm{~h}$. For purity control, $10 \mu 1$ of the inoculated suspension was uniformly 
spread on a nutrient agar plate and incubated at $37^{\circ} \mathrm{C}$ overnight, quality control strain was ran alongside the test strains.

\section{Reading of MIC}

The purity of the inoculum suspension was checked and confirmed to be pure before reporting the results. The plates were read by using the recommended record sheet for the plates, the growth in the 3 positive control wells were checked, the MIC was read and interpreted as the lowest concentration with no visible growth, caution was taken to read the sulphonamides and trimethoprim, with regards to these two antimicrobials the MIC was recorded as the lowest concentration where a reduction of growth by $80-90 \%$ can be observed.

Antimicrobials and resistance cut-off values/break point used in the study are as follows: Spectinomycin, (SPE) (R>64 mg/mL); streptomycin, (STR) $(\mathrm{R}>16 \mathrm{mg} / \mathrm{mL})$; sulfamethoxazole, (SMX) $(\mathrm{R}>256 \mathrm{mg} / \mathrm{mL})$; tetracycline, (TET) $(\mathrm{R}>8 \mathrm{mg} / \mathrm{mL})$; and trimethoprim, (TMP) $(\mathrm{R}>2 \mathrm{mg} / \mathrm{mL})$; ceftiofur, (XNL) $(\mathrm{R}>2 \mathrm{mg} / \mathrm{mL})$; chloramphenicol, (CHL) $(\mathrm{R}>16 \mathrm{mg} / \mathrm{mL})$; ciprofloxacin, (CIP) $(\mathrm{R}>0.06 \mathrm{mg} /$ $\mathrm{mL})$; colistin (COL) $(\mathrm{R}>8 \mathrm{mg} / \mathrm{mL})$; florfenicol, (FFN) $(\mathrm{R}>2 \mathrm{mg} / \mathrm{mL})$; gentamicin, (GEN) $(\mathrm{R}>2 \mathrm{mg} / \mathrm{mL})$; nalidixic acid, (NAL) (R>16 mg/mL); neomycin, (NEO) $(\mathrm{R}>8 \mathrm{mg} / \mathrm{mL})$; ampicillin, (AMP) $(\mathrm{R}>4 \mathrm{mg} /$ $\mathrm{mL}$ ); amoxicillin-clavulanic acid, (AUG) (R>4 mg/ $\mathrm{mL}$ ); apramycin, (APR) $(\mathrm{R}>4 \mathrm{mg} / \mathrm{mL})$.

Epidemiological cut-off values were interpreted in accordance to current European Committee on Antimicrobial Susceptibility Testing harmonized breakpoints (www.eucast.org) with the exceptions to interpretation of APR, AUG, COL, FFN, SPE, and XNL where Clinical and Laboratory Standards Institute [17] and clinical breakpoints were used, NEO and STR were interpreted according to research conducted at DTU-Food.

\section{Results}

From the 200 samples analyzed, 17 were positive for various species of Salmonella representing a prevalence of $8.5 \%$. Five serotypes comprising Salmonella Eko, Salmonella Uganda, Salmonella Amager, Salmonella Westhampton, and Salmonella Give were identified as shown in Table-1. On the basis of strain prevalence, Salmonella Eko constitutes 7 (41.2\%), Salmonella Uganda, 4 (23.5\%), Salmonella Amager, 2 (11.8\%), Salmonella Westhampton, 2 (11.8\%), and Salmonella Give, $2(11.8 \%)$ while the prevalence of serotypes on the basis of the sample types showed spleen and intestine presenting a higher incidence of serotypes, with $7(14.0 \%)$ and $6(12.0 \%)$ respectively, this is followed by feces $3(6.0 \%)$ and liver $1(2.0 \%)$ as presented in Table-1.

Most of the serotypes are sensitive to all the antibiotics with the exception of one Salmonella Amager isolate from spleen that exhibited resistance to streptomycin, and one each of Salmonella Uganda and
Table-1: Serotype-sample prevalence of Salmonella isolated from camel in Maiduguri, sub-Sahara Nigeria.

\begin{tabular}{llcc}
\hline $\begin{array}{l}\text { Serotypes/ } \\
\text { samples }\end{array}$ & $\begin{array}{l}\text { Specific serotype } \\
\text { identified }\end{array}$ & $\begin{array}{c}\text { No of } \\
\text { serotype } \\
\text { obtained }\end{array}$ & $\begin{array}{c}\text { Prevalence } \\
\text { in \% }\end{array}$ \\
\hline Serotypes & Salmonella Eko & 7 & 41.2 \\
& Salmonella Uganda & 4 & 23.5 \\
& Salmonella Amager & 2 & 11.8 \\
& Salmonella Give & 2 & 11.8 \\
& Salmonella & 2 & 11.8 \\
Total & Westhampton & 17 & 100.0 \\
Samples & Origin & & \\
& Spleen & 7 & 14.0 \\
& Intestine & 6 & 12.0 \\
& Faeces & 3 & 6.0 \\
Total & Liver & 1 & 2.0 \\
& & 17 & 100.0 \\
\hline
\end{tabular}

Salmonella Eko isolate from spleen and faeces respectively that exhibited resistance to sulfamethoxazole as shown in Table-2.

\section{Discussion}

This study report the isolation of Salmonella species from camel, this is the first report of these serotypes in camel from Maiduguri, sub-Sahara Africa. The study highlighted the possibility and potential risk of acquiring salmonellosis from consumption of camel meat slaughtered at the Maiduguri central abattoir, north eastern Nigeria. It also revealed the presence of Salmonella serotypes in a significant proportion $(8.5 \%)$ of camel in the north east of Nigeria. This outcome corroborated a previous work by Wernery and Kaaden [18], which classified camels as a reservoir for Salmonella infection; hence, camel meat could be a potential hazard for public health. Camels and its products could be a potential reservoir for salmonellosis not only for the camels but also to human and other animal species. Salmonella Eko, Salmonella Uganda, Salmonella Amager, Salmonella Westhampton, and Salmonella Give can therefore be classified as the major serotypes causing camel salmonellosis in Nigeria.

Salmonella serotypes obtained from this study are uncommon serotypes in Nigeria and have not been reported in camels as evidenced from several studies in the past. In United Arab Emirate, Salmonella Frintrop, and Salmonella Hind marsh as the most commonly incriminated and host adapted Salmonella serotypes from camel $[19,20]$. Similarly, study carried out between 1987 and 1991 by Wernery [21] implicated Salmonella Saintpaul, Salmonella Frintrop, and Salmonella Hindmarsh as the most frequent of Salmonella serotypes recovered from camel in UAE. Study carried out in Egypt by Mohammed and Suelam [22] reported Salmonella enteritidis and Salmonella typhimurium as the prevalent serotypes which are in contrast to the outcome of this study.

The overall Salmonella prevalence reported in various studies were at variance to the outcome of 


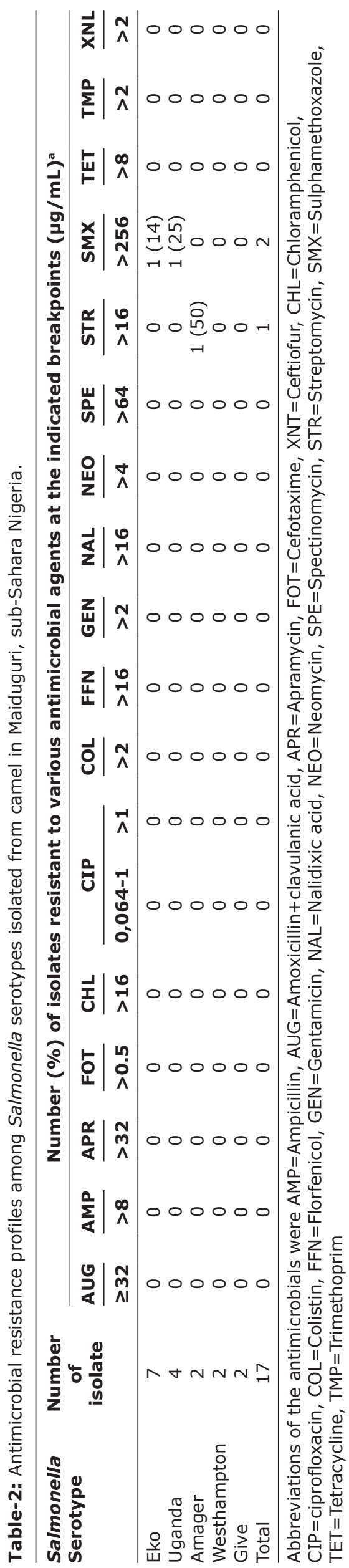

this study, though the disparities vary from one study to another, prevalence of $4.7 \%$ in UAE [21], 5.6\% in Egypt [22] and 7.4\% in UAE [19] these are lower when compared to $8.5 \%$ obtained from this study. Similar study in Ethiopia [10] reported an overall prevalence of $16.2 \%$.

This study reported a prevalence of fecal Salmonella to be $6 \%$, while $15.1 \%$ prevalence was reported in Ethiopia [10] 13.9\% in Egypt [22], and $4.3 \%$ in UAE [21].

Molla et al. [10] reported a prevalence of $11.8 \%$ from liver as against the $2 \%$ reported in this study and $0 \%$ reported by Mohammed and Suelam in Egypt. Previous studies on camel spleen reported a prevalence of $14.3 \%$ in Ethiopia [10] which is comparable to $14 \%$ from this study.

Camels like other animals can become a chronic carrier of Salmonella organisms and subsequently excretes the organisms in their feces intermittently, especially at times of stress such as during parturition, concurrent diseases, starvation, overcrowding and transport [22]. The carrier animals constitute a threat to camels and other species of animals; it can also become a health hazard to human through contact with contaminated carcasses or by ingestion of other contaminated edible products.

MDR Salmonella are of worldwide interest because they reduce the therapy options in human and veterinary medicine [6]. This study showed that MDR Salmonella were not incriminated in camel which indicates that the management system employed does not promote the indiscriminate use of antimicrobials or are being used as prescribed by the veterinary officer in charge. Furthermore, the susceptibility to important antimicrobials used for human/animals like fluoroquinolones and cephalosporins, is a positive development and this implies a need for the establishment of a coordinated surveillance, control and monitoring, program for Salmonella in the study area to prevent the establishment of resistance to these antimicrobials by the newly emerging serotypes.

\section{Conclusion}

The output of this study provides vital information on the camel as asymptomatic carriers of Salmonella in the study region, it equally revealed the trends in the prevalence of newly emerging or rarely reported Salmonella serotypes, and the antimicrobial resistance profile of Salmonella from camel in north east of Nigeria, this study can be adopted as a base for Salmonella control, prevention and therapeutic strategies.

\section{Authors' Contributions}

IAR, JAA, AA designed and planned this research work. IAR, GJA, IAO, FSO, IMG, UTK, MA collected samples, and performed laboratory investigation. IAR, IAO, JAA and AA drafted and revised the manuscript. All authors read and approved the final manuscript. 


\section{Acknowledgments}

The authors are grateful to all the staff and Miss Maria Louise Johannsen at the Technical University of Denmark (DTU-Food) for their supports and excellent technical assistance respectively. My appreciation also goes to the technical staff of the Department of Veterinary Microbiology, University of Maiduguri, Nigeria for the technical supports.

\section{Competing Interests} interests.

The authors declare that they have no competing

\section{References}

1. Anjum, M.F., Choudhary, S., Morrison, V., Snow, L.C., Mafura, M., Slickers, P., Ehricht, R. and Woodward, M.J. (2011) Identifying antimicrobial resistance genes of human clinical relevance within Salmonella isolated from food animals in Great Britain. J. Antimicrob. Chemother., 66(3): 550-559.

2. Hendriksen, R.S., Mikoleit, M., Kornschober, C., Rickert, R.L., Duyne, S.V., Kjelsø, C., Hasman, H., Cormican, M., Mevius, D., Threlfall, J., Angulo, F.J. and Aarestrup, F.M. (2009) Emergence of multidrug-resistant salmonella concord infections in Europe and the United States in children adopted from Ethiopia, 2003-2007. Pediatr. Infect. Dis. J., 28(9): 814-818.

3. Hendriksen, R.S., Vieira, A.R., Karlsmose, S., Lo Fo Wong, D.M., Jensen, A.B., Wegener, H.C. and Aarestrup, F.M. (2011) Global monitoring of Salmonella serotype distribution from the world health organization global foodborne infections network country data bank: Results of quality assured laboratories from 2001 to 2007. Foodborne Pathog. Dis., 8: 887-900.

4. Hendriksen, R.S., Le Hello, S., Bortolaia, V., Pulsrikarn, C., Nielsen, E.M., Pornruangmong, S., Chaichana, P., Svendsen, C.A., Weill, F.X. and Aarestrup, F.M. (2012) Characterization of isolates of Salmonella enterica serotype Stanley, a serotype endemic to Asia and associated with travel. J. Clin. Microbiol., 50(3): 709-720.

5. Majowicz, S.E., Musto, J. and Scallan, E. (2010) The global burden of nontyphoidal Salmonella gastroenteritis. Clin. Infect. Dis., 50(6): 882-889.

6. Bouchrif, B., Paglietti, B., Murgia, M., Piana, A., Cohen, N., Ennaji, M.M., Rubino, S. and Timinouni, M. (2009) Prevalence and antibiotic-resistance of Salmonella isolated from food in morocco. J. Infect. Dev. Ctries., 3(1): 35-40.

7. McEwen, S.A. and Fedorka-Cray, P.J. (2002) Antimicrobial use and resistance in animals. Clin. Infect. Dis., 34(3): 93-106.

8. World Health Organization. (2005) Drug-resistant Salmonella. In: World Health Organization., editor. Fact Sheet No. 193. World Health Organization, Geneva.

9. Salih, O., Mohamed, O. and Shigidi, M.T. (1998) The epidemiological factors associated with camel calf diarrhoea in Eastern Sudan. Proceedings: International Meeting on camel production and future perspectives. May 2-3. Faculty of Agricultural Science, Al Ain, UAE.

10. Molla, B., Alemayehu, D. and Salah, W. (2003) Sources and distribution of Salmonella serotypes isolated from food animals, slaughterhouse personnel and retail meat products in Ethiopia: 1997-2002. Ethiop. J. Health Dev., 17: 63.

11. Lynch, M., Painter, J., Woodruff, R., Braden C. and Centers for Disease Control and Prevention (CDC). (2006) Surveillance for foodborne - disease -outbreaks-United States, 1998-2002. MMWR Surveill Summ., 55(10): 1-42.

12. Foley, S.L. and Lynne, A.M. (2008) Food animal-associated Salmonella challenges: Pathogenicity and antimicrobial resistance. J. Anim. Sci., 86 E Suppl: E173-E187.

13. Le Hello, S., Hendriksen, R.S., Doublet, B., Fisher, I., Nielsen, E.M., Whichard, J.M., Bouchrif, B., Fashae, K., Granier, S.A., Silva, N.J., Cloeckaert, A., Threlfall, E.J, Angulo, F.J., Aarestrup, F.M., Wain, J. and Weill, F.X. (2011) International spread of an epidemic population of Salmonella enterica serotype Kentucky ST198 resistant to ciprofloxacin. J. Infect. Dis., 204(5): 675-684.

14. Cowan, S.T. and Steel, K.J. (1993) In: Barrow, G.I. and Feltham, R.K.A., editors. Manual for the Identification of Medical Bacteria. 3rd ed. Cambridge University Press, Cambridge.

15. Popoff, M.J. and Minor, L. (2007) Antigenic formulas of the Salmonella serotypes, 9th ed. WHO Collaborating Centre for Reference and Research on Salmonella, Institute Pasteur, Geneva, Paris, France.

16. Raufu, I., Hendriksen, R.S., Ameh, J.A. and Aarestrup, F.M. (2009) Occurrence and characterization of Salmonella hiduddify from chickens and poultry meat in Nigeria. Foodborne Pathog. Dis., 6(4): 425-430.

17. CLSI (Clinical and Laboratory Standards Institute). (2014) Performance standards for antimicrobial susceptibility testing, 24th Informational Supplement. CLSI Document M100-S24. Clinical and Laboratory Standards Institute, Wayne, PA.

18. Wernery, U. and Kaaden, O.R. (2002) Infectious Diseases in Camelids. Blackwell Science, Berlin Vienna.

19. Moore, J.E., McCalmont, M., Xu, J., Nation, G., Tinson, A.H., Crothers, L. and Harron, D.W. (2002) Prevalence of faecal pathogens in calves of racing camels (Camelus dromedarius) in the United Arab Emirates. Trop. Anim. Health Prod., 34(4): 283-287.

20. Sebastian, M., Peggy, B., Ulrich, W., Jörg, K., Michael, P., Antje, F., Erhard, T. and Wolfgang, R. (2012) Prevalence, serotypes, phage types, and antibiotic susceptibilities of Salmonella strains isolated from animals in the United Arab Emirates from 1996 to 2009. Trop. Anim. Health Prod., 44(7): 1725-1738.

21. Wernery, U. (1992). The prevalence of Salmonella infections in camels (Camelus dromedarius) in the United Arab Emirates. Br. Vet. J., 148(5): 445-450.

22. Mohamed, M.E.M. and Suelam, I.A. (2010) Isolation of non-typhoid Salmonella from humans and camels with reference to its survival in abattoir effluents. Glob. Vet., 5(6): 356-361. 